\title{
Possible overlap between reversible cerebral vasoconstriction syndrome and symptomatic vasospasm after aneurysmal subarachnoid hemorrhage
}

\author{
Patrice Forget • Pierre Goffette • \\ Françoise van de Wyngaert · Christian Raftopoulos • \\ Philippe Hantson
}

Received: 9 February 2009/Accepted: 1 April 2009/Published online: 21 April 2009

(C) Springer-Verlag 2009

\begin{abstract}
A 34-year-old woman with a previous history of severe headache ("thunderclap") was admitted with a diagnosis of aneurysmal subarachnoid hemorrhage (SAH). The patient developed symptomatic vasospasm on day 5 that resolved rapidly after having increased arterial blood pressure. She experienced also short-lasting excruciating headache. On day 12, while velocities had normalised, as revealed by transcranial Doppler (TCD), for more than $48 \mathrm{~h}$, she developed aphasia and right hemiplegia associated with diffuse segmental vasospasm on the left middle cerebral artery. Intra-arterial infusion of vasodilatory agents was required. Recurrence of symptomatic vasospasm was noted on day 25 , with a great number of territories involved as shown in the cerebral angiogram. A second intra-arterial treatment was needed. The patient complained of multiple episodes of extremely severe headache ("thunderclap"), with also transient dysarthria and hemiparesia on day 30. She was discharged on day 38 after full recovery. The clinical and TCD/radiological
\end{abstract}

P. Forget $\cdot$ P. Hantson $(\bowtie)$

Department of Intensive Care, Cliniques St-Luc,

Université catholique de Louvain, Avenue Hippocrate,

10, 1200 Brussels, Belgium

e-mail: philippe.hantson@uclouvain.be

P. Goffette

Department of Neuroradiology, Cliniques St-Luc,

Université catholique de Louvain, Brussels, Belgium

F. van de Wyngaert

Department of Neurology, Cliniques St-Luc,

Université catholique de Louvain, Brussels, Belgium

C. Raftopoulos

Department of Neurosurgery, Cliniques St-Luc,

Université catholique de Louvain, Brussels, Belgium findings were consistent with a reversible cerebral vasoconstriction syndrome overlapping SAH related symptomatic vasospasm.

Keywords Reversible cerebral vasoconstriction syndrome - Aneurysmal subarachnoid hemorrhage . Vasospasm

\section{Introduction}

Reversible cerebral vasoconstriction syndrome (RCVS) is a rare vasculopathy of unknown etiology $[1,2]$. It was mainly reported in young women with a history of severe "thunderclap" headache. The clinical picture may mimic subarachnoid hemorrhage (SAH). In addition, unruptured aneurysms have been reported in some patients with RCVS, but not clear causal relationship has been documented [3-5]. We describe a case of aneurysmal SAH for which the differential diagnosis has to be discussed between RCVS and symptomatic vasospasm.

\section{Case report}

A 34-year-old woman developed acute-onset occipital headache with loss of consciousness. She had a history of episodic severe headache treated by nonsteroidal antiinflammatory drugs. There was no clear precipitating factor. The headache was described as generalised and bilateral. The pain was excruciating and lasted usually less than $1 \mathrm{~h}$, being sometimes accompanied by nausea and vomiting.

On arrival, she had a GCS of 15 , and also with a mild hypo-esthesia in the left arm. The brain CT confirmed the 
diagnosis of SAH (Fisher 3 radiological score), with a focal hematoma in the territory of the left anterior cerebral artery (ACA), blood in the subarachnoid spaces of the left sylvian fissure and into the occipital horn of the left lateral ventricle. The cerebral angiography revealed four distinct aneurysms. The ruptured aneurysm $(8 \mathrm{~mm} \times 9 \mathrm{~mm})$ was located on the junction of the A1-A2 segments of the left ACA. The three unruptured aneurysms were on the A1 segment of the left ACA (1.5 mm diameter), on the A2 segment $(3 \mathrm{~mm} \times 2 \mathrm{~mm})$ and at the origin of the posterior communicating artery. The clipping of the four aneurysms was performed without peri-operative complications and after extubation the patient presented only neck stiffness and photophobia. She received oral nimodipine and continuous infusion of magnesium sulphate. On day 5 from bleeding, she was found drowsy, with a slurry speech, and a vasospasm on the left middle cerebral artery (MCA) was suspected on transcranial Doppler (TCD). Systolic arterial pressure was increased to $150 \mathrm{mmHg}$ by norepinephrine infusion followed by rapid neurological improvement. She complained on days 9 and 10 of acute-onset but shortlasting excruciating headache. Norepinephrine infusion was tapered down and stopped on day 12. Velocities normalised on TCD performed on days 7 and 10. She was discharged from ICU on day 12 with a normal neurological examination but was readmitted the same night with right hemiplegia and aphasia. The diffusion-weighted imaging (DWI) during brain MR showed a limited hyperintense lesion in the left cingulum. As the symptoms persisted after $12 \mathrm{~h}$ of intensive treatment, rescue therapy with intra-arterial vasodilatory agents was considered. Nimodipine ( $3 \mathrm{mg}$ over 20 min) was infused in loco (left MCA) during cerebral angiography, followed by intravenous continuous infusion of milrinone $(0.75 \mu \mathrm{g} / \mathrm{kg}$ per $\mathrm{min})$. There was a prompt recovery of aphasia and a regression of the motor deficit in the upper right limb. The patient was able to move the right lower limb on day 16. Milrinone infusion was continued for a period of 11 days, and during this treatment, norepinephrine infusion had to be increased to $2 \mu \mathrm{g} / \mathrm{kg}$ per min to obtain an arterial systolic blood pressure of $150 \mathrm{mmHg}$. The evolution of the clinical course and of the TCD/radiological investigations is summarised in Table 1. On day 25, the patient became drowsy and complained again from severe headache. Bilateral vasospasm was demonstrated by TCD and angiography (Fig. 1a, b). Intra-arterial infusion of milrinone $(15 \mathrm{mg}$ over $60 \mathrm{~min}$, divided in two doses in both MCA) was performed, and intravenous infusion was started again as in the previous episode, for a total of 5 days (together with high doses of norepinephrine). Symptoms regressed, except for headache (multiple episodes every day). Finally, on day 30, dysarthria and right hemiparesia were transiently noted. Magnesium sulphate infusion and norepinephrine (as a part of the triple $\mathrm{H}$ therapy) were stopped on day 32. The patient was discharged from the ICU on day 38 after a normal neurological examination but with persisting high velocities at TCD examination of the right MCA. The velocities normalised completely only on day 43 . The patient made a complete recovery (including headache) at 3 months follow-up.

\section{Discussion}

The idiopathic RCVS is a disease with cerebral vasoconstriction that is usually documented by CT or MR angiography. The syndrome should be differentiated from other identified causes of arterial narrowing including CNS vasculitis, pheochromocytoma or the use of vasoactive substances like cocaine $[1,2]$. In some patients, the presence of an associated intracranial abnormality can be demonstrated, as in our patient who had a ruptured aneurysm leading to SAH.

Obviously, vasospasm, symptomatic or not, is a common complication following aneurysmal SAH. The presence of blood close to the site of the aneurysm locally triggers the vasospasm. The maximal duration of vasospasm, when installed, is usually 4 weeks. However, a delayed recurrence of symptomatic vasospasm is infrequent. Also the clinical symptoms and the TCD and radiological findings were unusual. Recurrent excruciating headache ("thunderclap") was the main clinical feature. It lasted for approximately one hour and was poorly influenced by major analgesics. It occurred several times during the same journey and seemed to be partly correlated with increased velocities on TCD examination. Cerebral angiography demonstrated migrating segmental vasoconstriction in different cerebral arteries.

We suspected that cerebral vasoconstriction could be triggered by two different mechanisms and postulated that the patient presented an overlap between RCVS and SAHrelated vasospasm.

It has been suggested that some factors known to be involved in SAH-related vasospasm (catecholamines, endothelin-1, serotonin, nitric oxide, and prostaglandins) could play a similar role in the pathophysiology of vasoconstriction in RCVS [1, 2].

SAH without intracranial aneurysm is not infrequently encountered in RCVS, perhaps in up to one in four cases, and typically overlies the lateral-superior cortical surface [3-6]. In RCVS, SAH is usually minimal or moderate in amount and should not be considered the cause of the segmental vasoconstriction, which affects artery remote to the site of bleeding. An association between RCVS and unruptured intracranial aneurysm has also be reported [5].

By definition, RCVS usually shows diffuse areas of multiple stenosis and dilatation involving intracranial 
Table 1 Clinical course, TCD and radiological findings, and therapy

\begin{tabular}{|c|c|c|c|c|}
\hline Day from bleeding & $\begin{array}{l}\text { TCD } \\
\text { Mean velocity }(\mathrm{cm} / \mathrm{s}) \\
\text { (left MCA/right } \mathrm{MCA})\end{array}$ & Symptoms & $\begin{array}{l}\text { Brain CT or MR } \\
\text { angiography } \\
\text { Vasospasm }\end{array}$ & Treatment \\
\hline D1 & & $\begin{array}{l}\text { Headache, loss of } \\
\text { consciousness }\end{array}$ & & Nimodipine \\
\hline D2 & & (Clipping) & & Nimodipine, $\mathrm{MgSO}_{4}$ \\
\hline D3 & & & & Nimodipine, $\mathrm{MgSO}_{4}$ \\
\hline D4 & $130 / 111$ & Headache & & Nimodipine, $\mathrm{MgSO}_{4}$ \\
\hline D5 & $154 / 123$ & Headache & Left $\operatorname{MCA}(\mathrm{P})$ & Nimodipine, $\mathrm{MgSO}_{4}$, THT \\
\hline D6 & $160 / 135$ & & & Nimodipine, $\mathrm{MgSO}_{4}$, THT \\
\hline D7 & $105 / 88$ & & & Nimodipine, $\mathrm{MgSO}_{4}, \mathrm{THT}$ \\
\hline D8 & & & & Nimodipine, $\mathrm{MgSO}_{4}$, THT \\
\hline D9 & & & & Nimodipine, $\mathrm{MgSO}_{4}$, THT \\
\hline D10 & $95 / 88$ & & & Nimodipine, $\mathrm{MgSO}_{4}$, THT \\
\hline D11 & & & & Nimodipine, $\mathrm{MgSO}_{4}$ \\
\hline D12 & & & & Nimodipine, $\mathrm{MgSO}_{4}$ \\
\hline D13 & $174 / 109$ & Aphasia, right hemiplegia & $\begin{array}{r}\text { Left } \mathrm{ACA}(\mathrm{C}) \text {, diffuse } \mathrm{D} \text { on } \\
\text { left } \mathrm{M} 1 \text { and right } \mathrm{M} 1-\mathrm{M} 2\end{array}$ & $\begin{array}{l}\text { Nimodipine, } \mathrm{MgSO}_{4} \text {, THT-IA } \\
\text { nimodipine, IV milrinone }\end{array}$ \\
\hline D14 & $99 / 62$ & Right leg plegia & & Nimodipine, $\mathrm{MgSO}_{4}$, THT, milrinone \\
\hline \multirow[t]{2}{*}{ D15 } & $92 / 63$ & & & Nimodipine, $\mathrm{MgSO}_{4}$, THT, milrinone \\
\hline & & Motor recovery & & \\
\hline D16 & & & & Nimodipine, $\mathrm{MgSO}_{4}$, THT, milrinone \\
\hline D17 & $105 / 60$ & & & Nimodipine, $\mathrm{MgSO}_{4}$, THT, milrinone \\
\hline D18 & $140 / 60$ & Headache & & Nimodipine, $\mathrm{MgSO}_{4}$, THT, milrinone \\
\hline D19 & $145 / 88$ & Headache & & Nimodipine, $\mathrm{MgSO}_{4}$, THT, milrinone \\
\hline D20 & $121 / 80$ & & & Nimodipine, $\mathrm{MgSO}_{4}$, THT, milrinone \\
\hline $\mathrm{D} 21$ & $122 / 62$ & & & Nimodipine, $\mathrm{MgSO}_{4}$, THT, milrinone \\
\hline $\mathrm{D} 22$ & & & & Nimodipine, $\mathrm{MgSO}_{4}$, THT, milrinone \\
\hline $\mathrm{D} 23$ & & & & Nimodipine, $\mathrm{MgSO}_{4}$, THT, milrinone \\
\hline D24 & $89 / 71$ & & & Nimodipine, $\mathrm{MgSO}_{4}, \mathrm{THT}$ \\
\hline D25 & $150 / 220$ & $\begin{array}{l}\text { Confusion, agitation, } \\
\text { headache }+++\end{array}$ & See Fig. 1 & $\begin{array}{l}\text { Nimodipine, } \mathrm{MgSO}_{4} \text {, THT-IA + IV } \\
\text { milrinone }\end{array}$ \\
\hline D26 & $109 / 165$ & Headache & & Nimodipine, $\mathrm{MgSO}_{4}$, THT, milrinone \\
\hline $\mathrm{D} 27$ & $96 / 100$ & Headache & & Nimodipine, $\mathrm{MgSO}_{4}$, THT, milrinone \\
\hline D28 & $78 / 130$ & Headache & & Nimodipine, $\mathrm{MgSO}_{4}$, THT, milrinone \\
\hline D29 & & & & Nimodipine, $\mathrm{MgSO}_{4}$, THT, milrinone \\
\hline D30 & & $\begin{array}{l}\text { Transient dysarthria and } \\
\text { right hemiparesia }\end{array}$ & $\begin{array}{l}\text { RP1, focal BT, segmental } \\
\text { left M1, right M1 }\end{array}$ & Nimodipine, $\mathrm{MgSO}_{4}$, THT \\
\hline D31 & $96 / 166$ & & & Nimodipine, $\mathrm{MgSO}_{4}$, THT \\
\hline D32 & $83 / 152$ & & & Nimodipine, $\mathrm{MgSO}_{4}$, THT \\
\hline D33 & & & & Nimodipine \\
\hline D34 & $94 / 171$ & & & Nimodipine \\
\hline D35 & & & & Nimodipine \\
\hline D36 & & & & Nimodipine \\
\hline D37 & & & & Nimodipine \\
\hline D38 & $87 / 145$ & Full recovery & & Nimodipine \\
\hline
\end{tabular}

$\overline{T C D}$ transcranial Doppler, left ACA left anterior cerebral artery, left $M C A$ left middle cerebral artery, right $M C A$ right middle cerebral artery, $L M 1$ segment M1 of left MCA, RM1-2 segments 1-2 of right MCA, RP1 segment P1 of the right posterior cerebral artery, $B T$ basilar trunk, $P$ proximal, $C$ complete, $D$ distal, $T H T$ triple-H therapy, $I A$ intra-arterial (in loco), $I V$ intravenous 


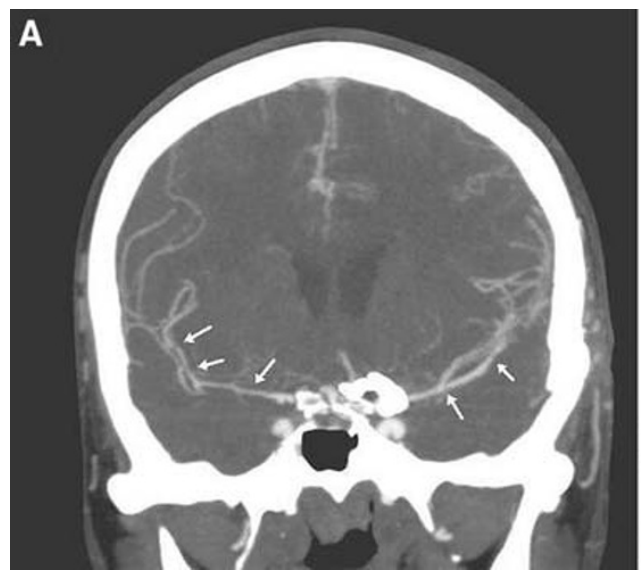

Fig. 1 Angio-CT, three-dimensional reconstruction, coronal view. a Diffuse segmental stenosis of the proximal and distal (arrows) right middle cerebral artery. Segmental stenosis of the distal (arrows) left

arteries $[1,2,6]$. These abnormalities are reversible within days to weeks. In SAH, vasospasm typically is not multifocal, affects one or two medium arteries, and peaks between days 4 and 11 .

The pharmacological treatment of SAH-related vasospasm relies on the so-called "triple-H therapy" (hypertension, hypervolemia, hemodilution), where hypertension induced by norepinephrine may play a major role. It can not be excluded that vasoactive substances like norepinephrine may aggravate RCVS [6]. The place of "rescue" therapy with intra-arterial vasodilatory agents is not yet defined [7].

\section{Conflict of interest None.}

\section{References}

1. Garcin B, Clouston J, Saines N (2009) Reversible cerebral vasoconstriction syndrome. J Clin Neurosci 16:147-150

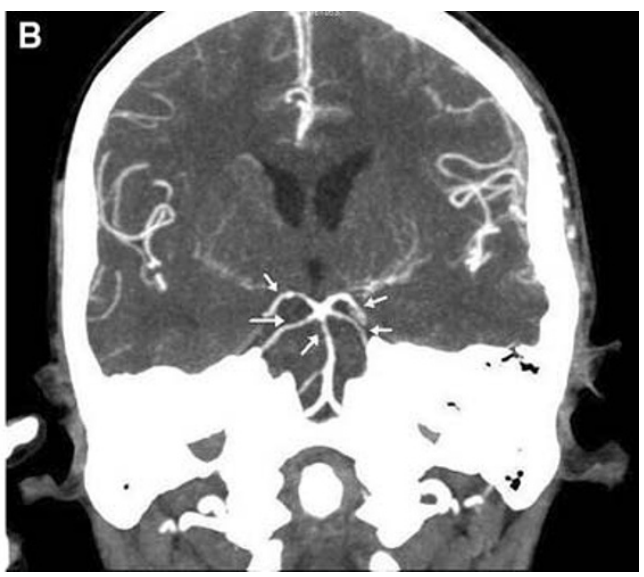

middle cerebral artery. b Diffuse narrowing (arrows) of the distal basilar trunk, of both posterior cerebral arteries, and of both superior and anterior cerebellar arteries

2. Valença MM, Andrade-Valença LP, Bordini CA, Speciali JG (2008) Thunderclap headache attributed to reversible cerebral vasoconstriction: view and review. J Headache Pain 5:277-288

3. Moustafa RR, Allen CMC, Baron J-C (2008) Call-Fleming syndrome associated with subarachnoid hemorrhage: three new cases. J Neurol Neurosurg Psychiatry 79:602-605

4. Nickele C, Muro K, Getch CC, Wallker MT, Bernstein RA (2007) Severe reversible cerebral vasoconstriction syndrome mimicking aneurysmal rupture and vasospasm. Neurocrit Care 7:81-85

5. Singhal AB (2002) Thunderclap headache, reversible cerebral arterial vasoconstriction, and unruptured aneurysms. J Neurol Neurosurg Psychiatry 73:96

6. Ducros A, Boukobza M, Porcher R, Sarov M, Valade D, Bousser M-G (2007) The clinical and radiological spectrum of reversible cerebral vasoconstriction syndrome. A prospective series of 67 patients. Brain 130:3091-3101

7. Fraticelli AT, Cholley BP, Losser MR, Maurice JP, Payen D (2008) Milrinone treatment of cerebral vasospasm after aneurismal subarachnoid hemorrhage. Stroke 39:893-898 